\title{
Development of Feedmill Auto-Formulator Software
}

\author{
Adewumi I0* and Adelekan BA \\ Department of Agricultural Engineering, Federal College of Agriculture, Nigeria \\ *Corresponding author: Adewumi IO, Department of Agricultural Engineering, Federal College of Agriculture, Moor Plantation, \\ Ibadan, Oyo State, Nigeria
}

\begin{abstract}
One of the problems confronting science and technology innovation and sustainability are ways of collecting, preserving, manipulating and presenting information on a desirable platform for ease of usage for the end-user. Utilization of Graphical User Interface Platform for Feed formulator in the feed mill industry has been identified as a major tool for proper scheduling, controlling, presenting and even archiving properly relative, necessary and important data in the feeds, Formula, operator among others. The materials used for the research work include; PHP programming language, Zinox corei7 Laptop, MySQL, XAMP server, JavaScript, Microsoft Office Software, Notepad++, Python Script, html5, and CSS. The incremental model which consists of linear and prototype was adopted for the development of the software. The Graphical User Interface was developed in PHP files integrated with HTML5 and uses an embedded database of MySQL, with the XAMP server as localhost. The code was segmented into four major sections; which includes the index, function, invoice file, and the database script. XAMP server was employed with google chrome browser to test the software. The output of the software consists of the user interface for input of the necessary ingredients with their relative price and quantities, invoice and administrative section to view the database was developed.
\end{abstract}

Keywords: Agriculture tourism village; Community based tourism; Natural resources

\section{Introduction}

Housing (2015) has observed that managing, exchanging, manipulating, and presenting data are some of the crucial activities in the context of information technology, engineering and computing. In engineering, the first encounter to computing is to normally introduce to the notion of "input, process, and output". extended Mark-up Language (XML) has been one of the standards for data communication within the software industry. According to Charles [1], feed mill quality assurance (QA) program ensures that any feed produced conforms to the company's nutritional and physical specifications when the product is sold or delivered. Quality assurance requires a comprehensive approach that encompasses the people, policies, and procedures involved in each stage of production-from purchasing ingredients to delivering the feed to a customer or farm. The content and details of a QA program will be based upon each company's needs and goals, and the equipment and manufacturing processes in the feed mill. An effective QA program addresses all phases of production-from a mill's quality specification for ingredients and their traceability, through manufacturing processes and packaging, to finished feed delivery. It defines critical control points for evaluating product quality.

Chernos and Schneider [2] Small poultry flock owners often experience problems of one sort or another with their young birds. In the majority of cases, the problems are related to either management or nutrition.

Jonge and Jackson [3] have opined that feed has a fundamental influence on productivity, health and welfare of the animal. Feed quality influences animal product quality and safety, and the environment. To achieve balance among these parameters, the animal's nutritional requirements must be properly met. Confidence in the nutritional information on any feed or feed ingredient provided by suppliers is critical for buyers because it provides a guarantee of feed quality. Current reports from many countries suggest that manufacturers and buyers do not always have confidence in the data provided for non-accredited laboratories, which can negatively affect market prices and international trade. It is therefore important that laboratories work towards adopting a Quality Assurance System for all of their routine feed analyses. 
Abayomi et al. [4] has researched on the productivity outlook for a multi-criteria animal feed formulation problem in Nigeria. The author noticed that over-formulation or under-formulation of animal feed is a major challenge in a feed milling operation in the country. While overfeeding unnecessarily increases the feed cost; underfeeding on the other hand reduces the performance of the animal and the overall productivity of the feed milling operation. The study, therefore addressed how a multi-criteria feed formulation affects the productivity of feed milling business with the use of mathematical programming in bringing about an optimal solution that is both economical and brings out the best energy yield. The solution procedure employed in the study was an iterative multi-objective optimization method. The optimization of the metabolizable energy and ration cost is solved iteratively using a non-differentiable interactive multi-objective bundlebased optimization method which will then result into different alternative optimal formulations. These alternatives were then evaluated using the multi-factored productivity techniques to determine the interactions between each of the optimal solutions. The performance of the four alternative optimal solutions (C ingredient) generated were factored into the productivity model together with other input factors such as the cost of fuel ( $\mathrm{C}$ fuel), cost of labour (C labour) and cost of packaging (C packaging).

The productivity index estimated from the four alternative optimal formulations includes 1.13, 1.144, 1.06, and 0.96 respectively. This shows that the optimal feed formulation generated in alternative 2 produces the highest profit (14.35\%) and hence highest productivity index (1.144). Hence, the multi-factored productivity index is therefore a measure of performance in a feed mill industry when considering the impact of feed formulation on the overall cost of production in a feed mill industry. Different researchers have worked on different mathematical models in solving various engineering problem. Models have been defines by Adewumi et al. [5] as a prototype for representation of reallife situation. Models are useless if they cannot be interpreted to solve real life situation. Adewumi et al. [5] studied the level of ICT (information and communication technology) tools involvement in poultry brooding system among poultry farmers in Ido Local Government Area of Oyo State, Nigeria. 30 respondents were randomly selected for the study. Structured questionnaire and interview schedule were used to collect data (primary data) from the selected poultry farmers, also Journals, Magazine, Federal Office of Statistic Bulletins as well as the internet served as source of secondary data.

Data collected was analyzed with aid of frequency counts and percentages as descriptive statistical tools, while Chi-square $(\chi 2)$ analysis was used as inferential statistical tool. The results of analysis showed that majority $(76.7 \%)$ of the respondents are male, between the ages of 21-30 years (43.3\%), mostly single (60\%) and well educated $(70 \%)$ with good years of brooding experience. Epileptic power supply, poor mobile network, lack of availability of ICT tools, and High cost of ICT tools at percentage level of $40 \%$, $23.3 \%, 20.0 \%$, and $16.7 \%$ respectively are the major constraints encountered by the respondents in the use of ICTs in the area. The result of the Chi-square analysis ( $\chi 2$ ) shows that age $(r=0.021$;
$\mathrm{P}<0.05)$, religion $(\mathrm{r}=0.00304 ; \mathrm{P}<0.05)$, and $\operatorname{sex}(\mathrm{r}=0.0035 ; \mathrm{P}<0.05)$ exhibited a positive and significant relationship with the use of ICT tools while educational background $(r=1.74 \mathrm{E}-07 ; \mathrm{P}<0.05)$ and ethnic group $(\mathrm{r}=1.39 \mathrm{E}-14 ; \mathrm{P}<0.05)$ are not significant. The study recommends, among others, that government should encourage the use of ICTs among the poultry farmers in the area and in Nigeria at large through its inclusion in the agricultural extension program curriculum of different states. Also, Nigeria Engineers should be involved in the development of relevant software in solving the problem.

The focus of this research work is to translate model that has been developed by FAO for feed formulation into a friendly platform for users (Graphical User Interface). This will enable both expert and non-expert in the field of animal production to easily produce balanced feed for livestock production. Abayomi et al. [4] researched on productivity outlook for a multi-criteria animal feed formulation problem, with a case study of Nigerian Feed Mill Industry. The authors discussed common practices in feed formulation, which are majorly constant and fixed nutrition. Also different formulation techniques of feed have been reported by many researchers, which includes; manual techniques of feed formulation using Pearson's Square Method (PSM) as reported by Afolayan and Afolayan [6], trial and error method, using excel spreadsheet, mathematical single-linear programming approach, linear programming model assuming fixed nutritive values, among others as revealed by Oladokun and Johnson [7]. With all the models developed, there is need for development of a software for the Graphical User's Interface, in order to achieve reality of all the developed models by different researchers' home and abroad. The software will help local farmers in running their day to day activities of their poultry farm and also helps in proper or detailed accounting method for the farmers.

\section{Methodology}

The research work focus on development of software for Feed mill Unit of the Federal College of Agriculture, Moor Plantation Ibadan. The development software used was donated to the College by Nigerian Communications Commission (NCC), Abuja and National Information Technology Development Agency (NITDA), Abuja [8].

\section{Materials}

The materials used for the research work include; PHP programming language, Zinox corei7 Laptop, MySQL, XAMP server, JavaScript, Microsoft Office Software, Notepad++, Python Script, html5, and CSS.

\section{Methods}

The model development follows the standard incremental model, which comprises of the combination of linear sequential model and prototype. Rather than deliver the system as a single delivery, the development and delivery was broken down into increments with each increment delivering part of the required functionality. The structured set of activities employed in this research work includes the specification, design, validation and evolution has earlier reported by Einstein. The software requirement 
analysis follows the understanding of the problem domain which is the standard feed formula which has been developed with different mathematical models. The main user need is the Graphical User Interface (GUI) which will be like a platform for the end user. The basic function has been coded with PHP. Multi-step process was involved to determine the architecture, interface, data structures with necessary functional details. Machine readable and executable form was developed. The end user phase was designed in such a way that can add some useful information like name of the sales representative, amount paid, balance given out among others. The Graphical User Interface was developed in PHP files integrated with HTML5 and uses an embedded database of MySQL, with the
XAMP server as localhost. The code was segmented into four major sections; which includes the index, function, invoice file, and the database script.

\section{Testing}

After writing the necessary PhP and HTML code has shown in the Appendix. The software was tested unit by unit based on the incremental model adopted by installing and launching XAMP Server. MySQL Admin on the server was properly configured to serve as a localhost on port 3306 with PID 2180. Also, Apache server was launched on the XAMP server with PID 2596 as shown in Figure 1.

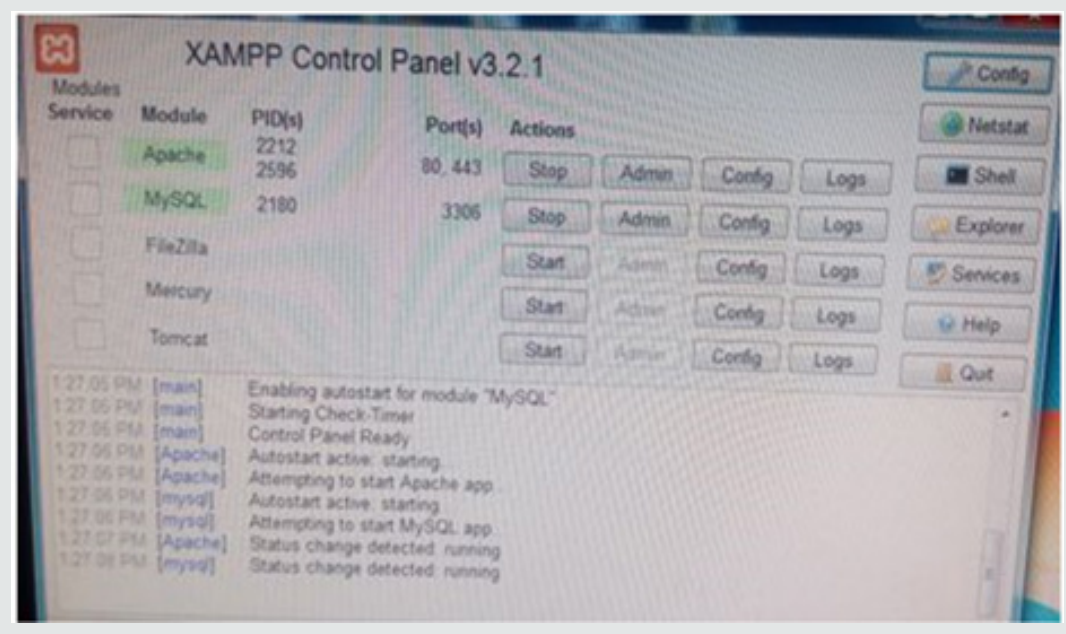

Figure 1: The XAMP Server.

\section{Results and Discussion}

The interface design will allow the end user to input ingredients with their quantity and unit price, whereby the developed software will calculate the total amount of the feeds and gives the feed analysis. The ingredients include; maize, sorghum, fishmeal (72\%), Fishmeal (65\%), soya meal, PKC, SBC, GNC, Concentrated layer, Concentrated broiler, Sp.grains, Ascorbic acid, whole wheat, vitamin $\mathrm{C}$, wheat offal, maize bran, rice bran, bone meal, Oyster shell, Limestone, Lysine, Methionine, Premix, Salt, Idomie which was programmed on the y-axis of the platform. While Ingredient, Total price, Price, Quantity, ME, Protein, Fat, Fiber, Calcium, Average Phosphorous, Lysine, Methionine on x-axis of the platform. The latter mentioned (on x-axis) will be inputted on the platform whereby their percentage analysis will be calculated by the developed feed mill software. The software has both logo of Federal Republic of Nigeria and Federal College of Agriculture, Moor Plantation, Ibadan, first name, last names and phone number of the client will be also captured, as showed in Figure 2.

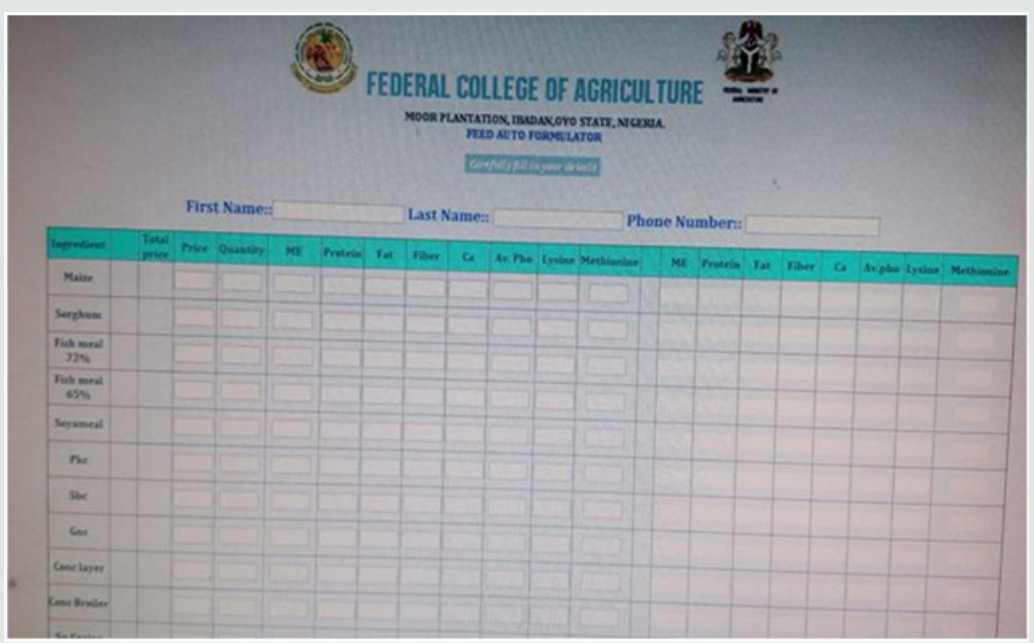

Figure 2: The Feedmill Interface for Enduser (Without any input). 


\section{Invoice}

PHP code which has been developed in invoice section will now run as at when the end-user clicks on PRINT INVOICE. The invoice consists of the header, invoice number, customer id, date, name of farm, Sales Personnel, s/n, description of item, quantity (kg), unit price in Naira. While the footer of the invoice page consists of the calculated analysis, which include the crude protein, available phosphorous, fats, calcium, lysine, net energy and methisoine (Figures 3a \& 3b). The receipt account details include receipt number, reference number, total amount paid during transaction, amount paid on sales, amount paid into account, amount paid from account and account balance, which has to be inputted by the sale representative manually. See Figure 4 for the output of the invoice and appendix for the PHP code.

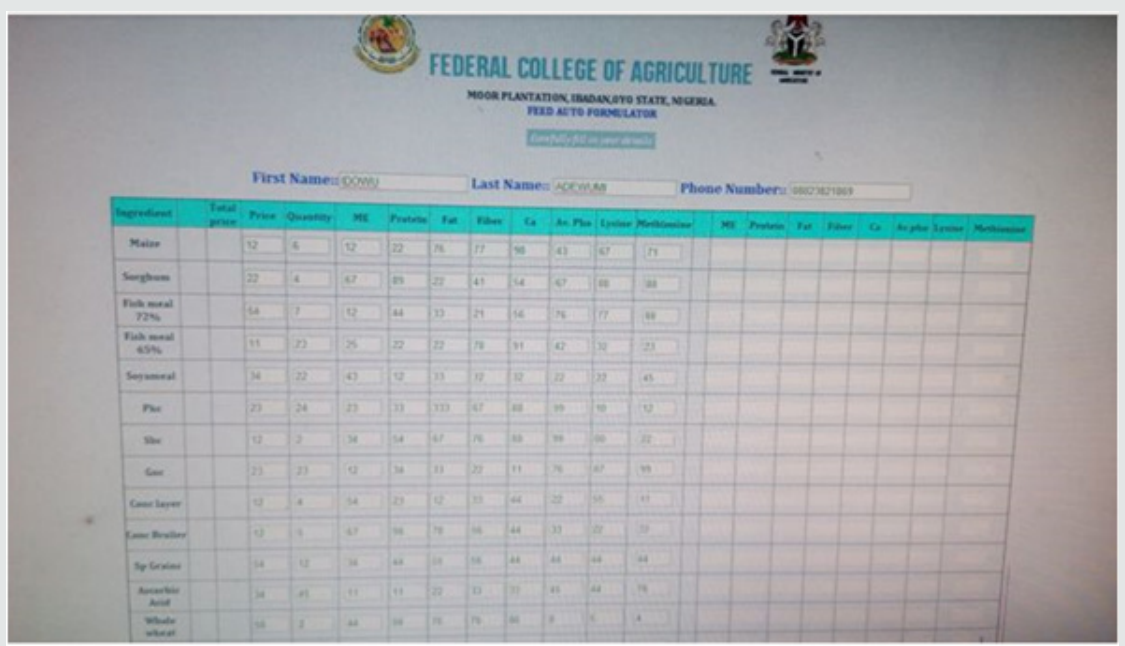

Figure 3a: The Developed Feedmill Interface for Enduser (With input).

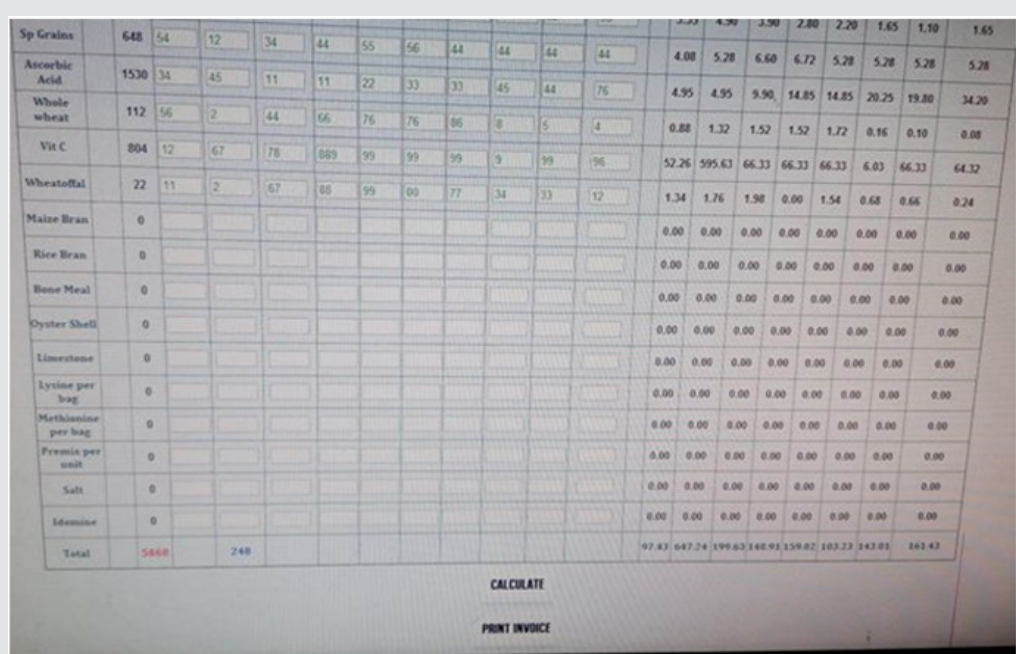

Figure 3b: The Developed Feedmill Software Interface for Enduser (Footer).

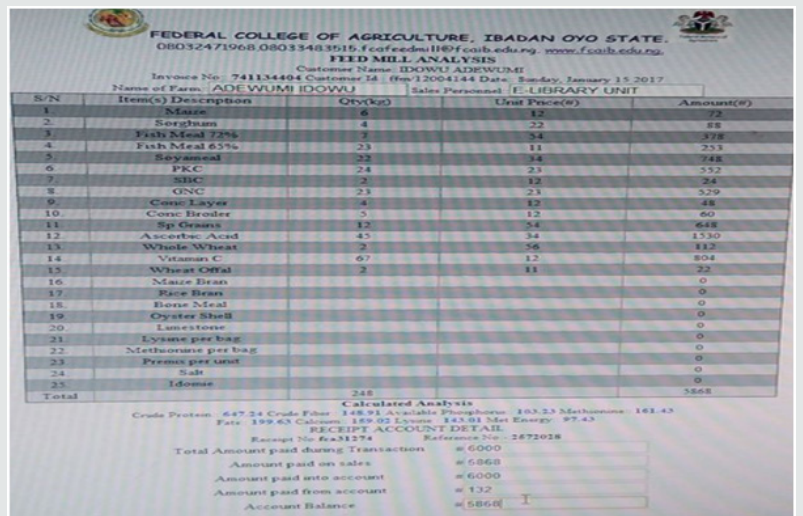

Figure 4: Invoice Generated with Calculated Feed Analysis. 


\section{Administrative Section}

The software was developed with a database in order to achieve the data generated from each client. Therefore, another file was developed with PHP for the administrative area, whereby the software manager can view all transactions in the database of the software. Figures $5 \mathrm{a} \& 5 \mathrm{~b}$ shows the interface of the administrator while the appendix shows the code file.

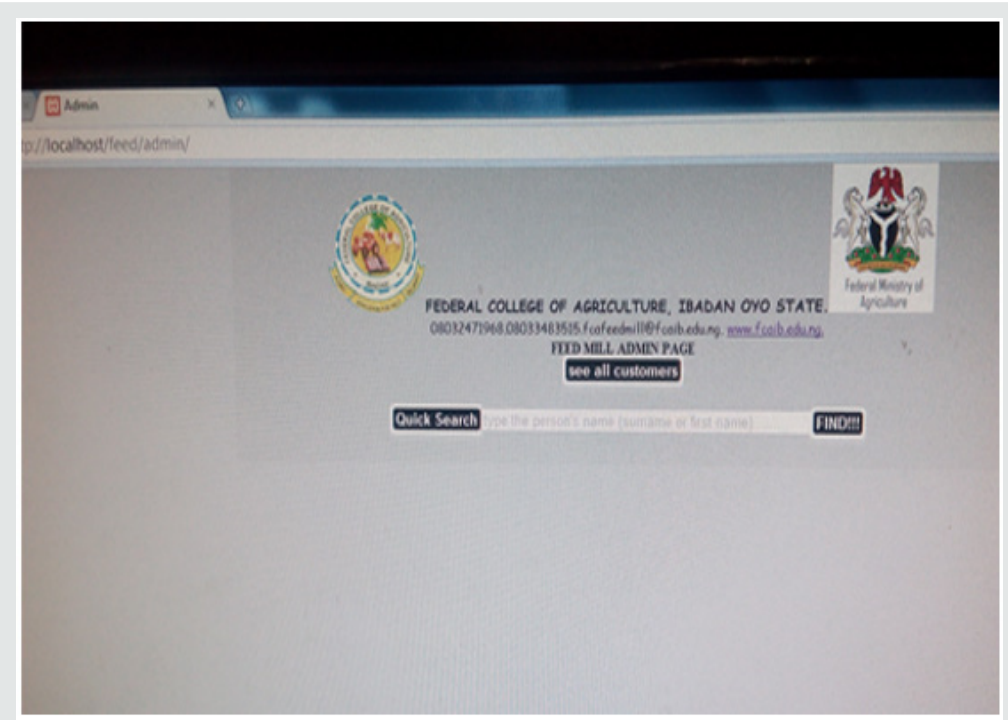

Figure 5a: The Admin Panel of the Developed Feedmill Software.

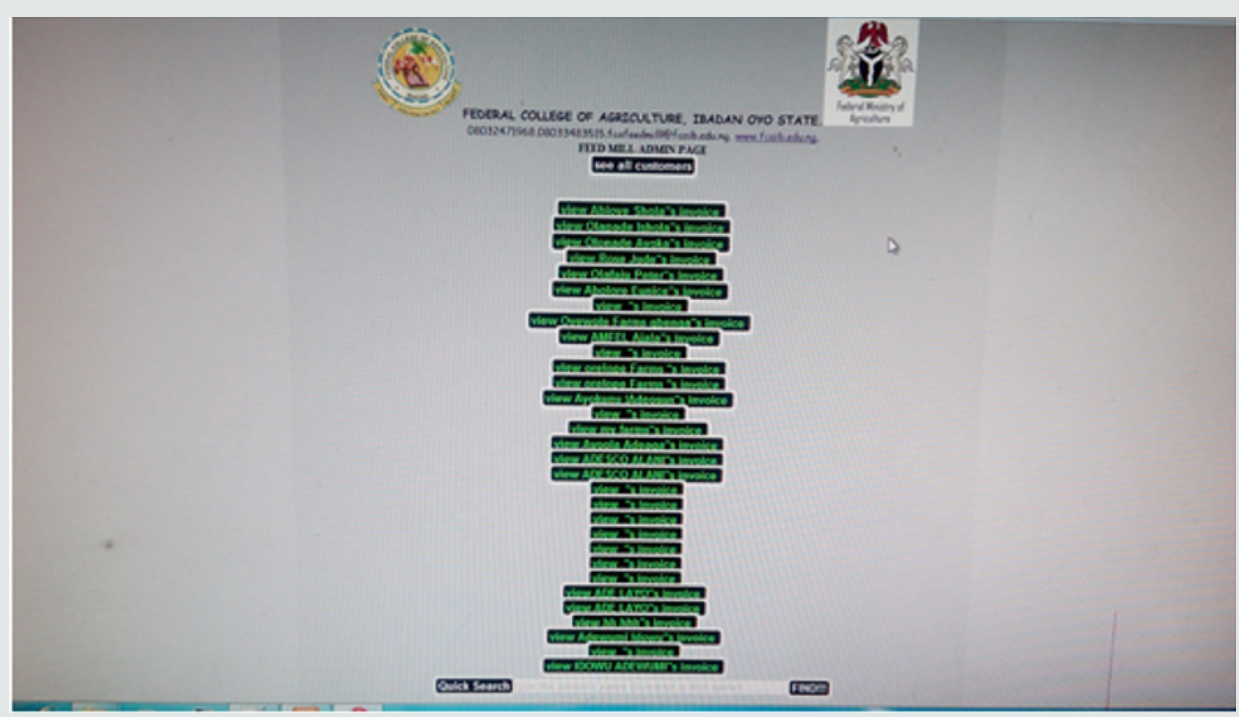

Figure 5b: The Admin Panel of the Developed Feedmill Software (Database).

\section{Conclusion and Recommendations}

In conclusion the aim and objective of this research work, which is development of feed mill software for Federal College of Agriculture, Ibadan was achieved. It is important to note that the developed software will definitely help local farmers and feed mill operators in the country to move agriculture forward and also help in the area of food sustainability. The author hereby recommends that the software should be deployed for various feed mill operators in the country with adequate training on the use of the tool. Government should encourage developers in terms of financial and technical know-how support, for them to use technology to deliver agriculture in Nigeria.

\section{References}

1. Charles S (2013) Feed Milling-Developing a Feed Quality Assurance Program. Publication of North Carolina Cooperative Extension, College of Agriculture and Life Sciences.

2. Chernos RJ, Schneider B (2004) Basic Poultry Brooding for Small Flock Owners. Practical Information Bulletin for Alberta's Agriculture Industry.

3. Jonge LH, Jackson FS (2013) The Feed Analysis Laboratory: Establishment and Quality Control. Setting up a feed analysis laboratory, and implementing a quality assurance system compliant with ISO/ IEC 17025:2005. H.P.S. Makkar, (Eds.), Animal Production and Health Guidelines No. 15. Rome, FAO.

4. Abayomi 00, Temitope AK, Oyelayo 0, Oluseye AA (2015) A Productivity Outlook for a Multi-Criteria Animal Feed Formulation Problem: A Case Study of Nigerian Feed Mill Industry. Int J Adv Technol 6(2): 145. 
5. Adewumi IO, Oluwatoyinbo FI, Augustus EO, Oladejo LF, Aremu DO (2013) Investigation of ICT Tools in Poultry Brooding System. International Journal of Innovative Research and Development 2(13) 110.

6. Afolayan MO, Afolayan M (2008) Nigeria Oriented Poultry Feed Formulation Software Requirements. Journal of Applied Sciences Research 4: 1596-1602.
7. Oladokun VO, Johnson (2012) Feed Formulation Problem in Nigeria Farms: A Mathematical Programming Approach. Am J Scilnd Res 3: 1420.

8. Hossein H (2015) Understanding XML: A Software Development Approach. ISBN 979-87-403-0988-1: 13

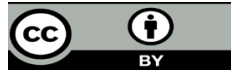

This work is licensed under Creative Commons Attribution 4.0 License

To Submit Your Article Click Here:

Submit Article

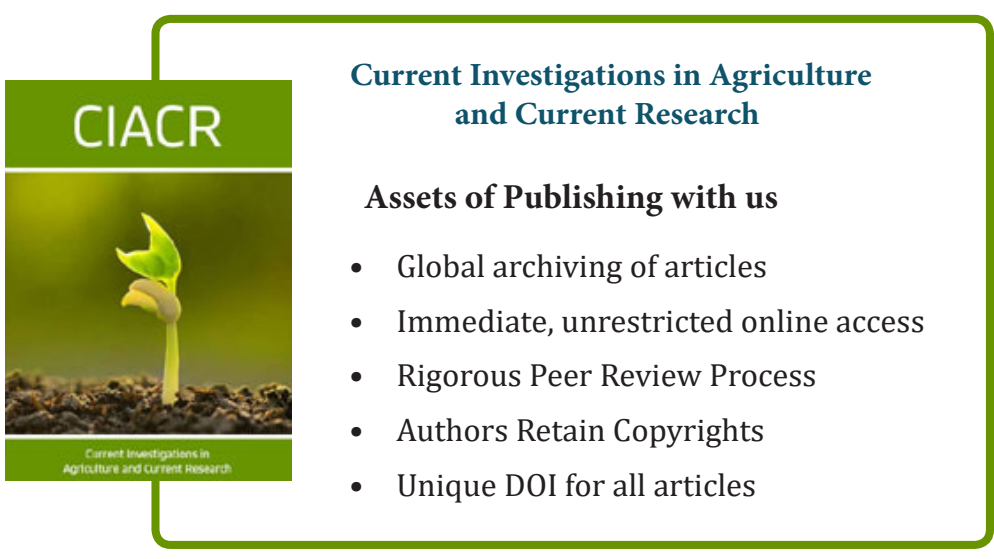

